\title{
Commonly Used Antimalarial Drugs in Calabar Metropolis, Nigeria
}

\section{Mbah $\mathrm{M}^{*}$, Sunday OI and Mark 00}

Department of Medical Laboratory Science, University of Calabar, Nigeria

*Corresponding author: Maurice Mbah, Department of Medical Laboratory Science, Faculty of Allied Medical Sciences, University of Calabar, Calabar, Nigeria; Email: mauricembah@yahoo.fr

\section{Research Article \\ Volume 4 Issue 1}

Received Date: April 10, 2020

Published Date: May 07, 2020

DOI: $10.23880 /$ jidtm- 16000138

\section{Abstract}

Malaria is a disease transmitted from person to person through the bite of a female Anopheles mosquito. Successful malaria control depends heavily on efficacious anti-malarial drugs. The manners in which anti-malaria drugs are used among urban dwellers contribute immensely to the development of resistant strain and therapeutic failure. This review was a descriptive Cross-sectional study carried out to assess anti-malarial drug use among urban dwellers in Calabar Municipality in Cross River State, Nigeria. Three hundred and eighty structured questionnaires were administered randomly to access the attitude and knowledge of respondents in terms of drugs preference, attitude to drug use and the effect of non-compliance to anti-malarial drugs. A total of 355 questionnaires were retrieved from the respondents. On the other hand, 60 questionnaires were also distributed to drugs vendors to access the most prescribed type of drugs and the attitude of customers as regards the type and choices of drugs acquisition. Of the 27 types of anti-malarial drugs sold in the pharmacies and chemist stores, Lonart 15(14\%) was the most common drug sold, followed by Amatem 10(9\%), while Maloxine was not sold at all in the pharmacies. In the chemist stores, Lonart $12(13 \%)$ and Coartem $9(9 \%)$ were the most often sold drugs while Halfan and Clomaxine were not sold at all. In the monthly prescriptions, Lonart $876(12 \%)$ was the most often prescribed drug followed by Coartem 628(9\%) and Amatem 600(8\%) while the least often prescribed drugs were Artemether, Clomaxine, Halfan and Atequine. Based on Doctors' recommendation, Lumartem 38(14\%) was the most frequently sold drug followed by P-Alaxin 33(12\%). The results of the survey have shown that Lonart, Coartem, Lumartem, Amatem and P-Alaxin were the most commonly sold and prescribed anti-malarial drugs.

Keywords: Tropical parasitic diseases; Antimalarial medicines; Drugs; Self-medication; Plasmodium; Anemia

Abbreviations: ACT: Artemisinin-based Combination Therapy; NIAID: National Institute of Allergy and Infectious Diseases; WHO: World Health Organization.

\section{Introduction}

\section{Background of the Study}

Malaria is a disease of the blood that is caused by the Plasmodium parasite, which is transmitted from person to person by female Anopheles mosquitoes [1]. Malaria is one of the major tropical parasitic diseases responsible for significant morbidity and mortality especially among children and pregnant women [2]. It is estimated that
1-2 million people die yearly as a result of malaria [3]. Africa faces the greatest impact of this disease [4]. The seriousness and gravity of this vector-borne disease cannot be overemphasized, given that about 3.4 billion people are at risk, of which 1.2 billion are at high risk. This led to an estimated 207 million clinical cases which resulted in about 627000 deaths in 2012, 90\% of which occurred in subSaharan Africa [5].

Malaria is highly endemic in Nigeria where it accounts for $60 \%$ outpatient visits to health facilities, $30 \%$ childhood and $11 \%$ of maternal dead (4,500 died yearly) [6]. It is also holoendemic in Nigeria [7]. WHO estimated that 100 million malaria cases with over 300,000 deaths occur yearly in 
Nigeria [5]. According to Federal Ministry of Health Abuja, financial loss due to malaria annually is estimated to be about 132 billion naira in form of treatment cost, prevention, loss of man-hour etc. Also the Society for Family Health stated that malaria has the highest burden of disease in Nigeria with an estimated 300,000 children dying of malaria each year and at least $50 \%$ of the population has at least one episode of malaria annually. Studies conducted recently in Calabar showed the overall high prevalence of malaria $(80.8 \%)$ which is similar to figure in Sierra Leone [8].

It is a tropical disease transmitted by the female Anopheles mosquito of which Anopheles gambiae is the most efficient vector. Mostly in Nigeria, malaria infection occurs through Plasmodium falciparum accounting for $98 \%$ of morbidity and mortality. Both adults and children are at risk with a higher incidence in children under the age of 5 years [2]. According to the World Health Organization report $2016,56 \%$ of the world population lives in malaria endemic regions and each year 300-500 million cases of malaria occur and more than one million people die of malaria [9].

Malaria is an irresistible public health problem. The number of cases of malaria worldwide appears to be growing because of the increasing risk of transmission in areas where malaria control has declined, increasing prevalence of drugresistant strains of parasites e.g. chloroquine resistance, which is linked to multiple mutations in transporter protein (PfCRT) and because of increasing international travel. Among four species of malarial parasites $P$. falciparum is responsible for severe illnesses and deaths whereas other species include $P$. vivax, $P$. ovale and P. malariae, cause mainly a febrile illness and only rarely lead to severe disease.

Majority of malaria cases worldwide are mild and can be treated with oral drugs referred to as anti-malarial drugs which substances are taken to fight against malaria, but delay in diagnosis or ineffective treatment may develop life-threatening complications requiring parenteral therapy [10]. The four major drug classes currently used to treat malaria include quinoline-related compounds, antifolates, artemisinin derivatives, and antimicrobials. Therefore, one or more classes of drugs often are given at the same time to combat malarial infection synergistically. Treatment regimens are dependent on the geographic location of infection, the likely Plasmodium species, and the severity of disease presentation [11].

Antimalarial drugs can be classified biologically as tissue schizontocidal used for prophylaxis e.g. pyrimethamine and primaquine, for preventing relapse, primaquine is the prototype drug, pyrimethamine also has such activity then blood schizonticides includes chloroquine, quinine, mefloquine, tetracyclines sulfones, halofantrine, pyrimethamine, sulphadoxine etc, gametocytocides include chloroquine quinine, primaquine and sporontocides i.e. primaquine and chloroguanide [12]. WHO issued a statement that led to a major change in the treatment of malaria. Monotherapy antimalarial medicines are not recommended, treatment must be used in combination i.e Artemether-Lumefantrine and in the rare case of a patient not responding to ACT (Artemisinin-based Combination Therapy), Quinine is recommended. Other ACTs available include Artesunate plus amodiaquine, Artesunate plus mefloquine and Dihydroartemisinin plus piperaquine and trimethoprim combinations.

Most recently Anthony KM, et al. [13] reported low proportion of malaria patients in receiving appropriate ACT treatment. This was due to inadequate education regarding malaria treatment, the practice of presumptive therapies, and lack of knowledge that Coartem (R) was the recommended first-line treatment for malaria. The two artemisinin compounds had the broadest time window of action and may be particularly suitable for the treatment of severe malaria. Malaria continues to be a potentially fatal threat to almost half of the world's population. Despite this threat, the armory to fight this disease is rather limited. Resistance against the most common and affordable anti-malarials are widespread. Only few new drugs are in clinical development, most of them belong to long used classes of anti-malarial drugs [14].

The problem of controlling malaria has become more complex over the last few years with the increase in resistance to the drugs normally used to combat the parasite that causes the disease. Pattern of drug-use in cases of malaria infection either on prescription basis or self-medication can result in high incidence of resistance strain [15]. The knowledge and attitude of patient can influence drug-therapy. Studies in Africa have shown that the initial treatment of malaria often takes place at home without consulting trained professionals [16]. Although, home treatment or self-medication has the potential of positively impacting on malaria control, in terms of prompt recognition and treatment to prevent complication and reduce mortality [17], the effectiveness of home treatment will depend on early recognition of symptoms and prompt commencement of appropriate treatment to ensure better outcome and prevent progression to severe malaria [15].

\section{Statement of the Problem}

Successful malaria control depends heavily on efficacious anti-malarial drugs for the treatment of malaria. The use of drugs for malaria treatment or prevention with the development of resistance and recent advances in molecular biology facilitate the evaluation of the impact on drugs resistance of new drug-base strategies? Nigeria 
is faced with a crisis of rising levels of resistance to antimalarial drugs and few available and affordable alternatives. However, combination therapy using two or more drugs with different mechanisms and site action together is proposed as a mechanism for slowing the process of development of resistance which has resulted in a sustained increase in the cure rate.

Most infections are treated presumptively on the basis of symptoms rather than a positive blood test. This leads to huge amount of over diagnosis and consumption of unnecessary and costly drugs. Self- treatment with medicine purchased from local store or pharmacy, which probably amounted to about $50 \%$ of drug use in Africa, may lead to the use of inappropriate drugs or under- dosing. Another serious issue is the wide spread use of substandard antimalarial drugs which has negative impact on users and also reduced the rate of effective treatment.

\section{Justification}

Having observed from various studies, malaria is as old as human itself and it is sometimes referred to as the "king of disease". This has continued to hunt and taunt mankind. Due to this menace, several individuals have resorted to various means to combat the disease ranging from approved and unapproved means. In the chase of these, several antimalarials are being purchased and used by individuals hence; there is need for this work.

\section{Scope of the study}

This review focuses on all the available antimalarial drugs purchased by individuals in pharmacies and chemist stores. It also includes both the prescribed and un-prescribed antimalarial drugs.

\section{Aim and Objectives}

The aim and objectives of this review work include the following:

To know the commonly used anti-malarial drugs in Calabar Municipal.

To evaluate the preferential choice of prescription of the anti-malarial drugs by doctors, pharmacists and chemists.

\section{Overview of Malaria}

The term malaria is derived from the Italian word "mal" or bad and "aria" or air. It meant foul or bad air as people initially noted that by shuttering up the houses and not going out in the evening reduced the risk from the gases of the swamp and risk of malaria [18]. Malaria is caused by infection with protozoan parasites belonging to the genus Plasmodium transmitted by female Anopheles species mosquitoes (Henry et al., 2012). According to CashinGarbutt, Alphonse Laveran, a French military physician, discovered the protozoan parasite in 1880, whilst working in Algeria. He was lauded with the Nobel Prize for this in 1907. Grassi and Filetti, Italian researchers named Plasmodium vivax, and Plasmodium malariae in 1890, and an American, Welch, named Plasmodium falciparum in 1897 [19]. Stephens named the last of the four, $P$. ovale, in 1922. It was Sir Ronald Ross, an officer in the Indian Medical Service who discovered the transmission of malaria by mosquito from bird to bird in 1897 in Calcutta, India, earning the Nobel Prize in 1902 [20].

Malaria is caused by infection with five species of Plasmodium the life cycles of which are very similar. Infection begins when sporozoites, the infective stages, are injected by a mosquito and are carried around the body until they invade liver hepatocytes where they undergo a phase of asexual multiplication (exoerythrocytic schizogony) resulting in the production of many uninucleate merozoites [21]. These merozoites flood out into the blood and invade red blood cells where they initiate a second phase of asexual multiplication (erythrocytic schizogony) resulting in the production of about 8-16 merozoites which invade new red blood cells. This process is repeated almost indefinitely and isresponsible for the disease, malaria. As the infection progresses, some young merozoites develop into male and female gametocytes that circulate in the peripheral blood until they are taken up by a female anopheline mosquito when it feeds [22]. Within the mosquito the gametocytes mature into male and female gametes, fertilization occurs and a motile zygote (ookinete) is formed within the lumen of the mosquito gut, the beginning of a process known as sporogony. The ookinete penetrates the gut wall and becomes a conspicuous oocyst within which another phase of multiplication occurs resulting in the formation of sporozoites that migrate to the salivary glands of a mosquito and are injected when themosquito feeds on a new host [23] (Figure 1).

According to Tricia M [24], malarial infections are characterized by paroxysms, or recurrent attacks, that develop in three stages, according to the National Institute of Allergy and Infectious Diseases (NIAID). The first stage of these attacks is the development of chills. Moderate to severe shaking chills may be accompanied by a headache, general ill feeling (malaise), fatigue, muscle pain, nausea, vomiting and diarrhea. Stage 2, fever, typically develops within an hour or two of initial symptoms and may cause hot and dry skin. As body temperature falls [24]. Stage 3, sweating, begins, causing feelings of extreme fatigue and weakness. These symptoms generally appear within ten to 16 days after the infectious mosquito bite and occur as a result of the bursting of infected red blood cells.

According to the NIAID, the presentation of symptoms 
of malaria may differ depending upon the parasite that caused the infection. Plasmodium falciparum malaria often develops suddenly and is associated with the most severe complications. People with $P$. falciparum malaria may feel miserable between attacks and may die without treatment. Infection ranges from asymptomatic infection to fatal disease [25]. On the other hand, those with Plasmodium vivax malaria, a geographically widespread type of malaria that produces less severe symptoms but that can recur for up to 3 years, may feel fine in between attacks. It is also characterized by relapses of malaria arising from persistent liver stages of the parasite (hypnozoite) [26]. Plasmodium malariae infections can produce typical malaria symptoms, but the parasite may lie dormant in the blood for decades, and even those with no symptoms can spread the infection through blood donation or mosquito bites. Plasmodium ovale infections are very rare (occurring mainly in West Africa) and may cause relapses.

Both $P$. vivax and $P$. ovale infections are characterized by attacks that recur regularly every two days, while $P$. malariae is associated with recurrences occurring every three days [27]. Infection with $P$. falciparum will most likely lead to serious, potentially fatal complications. $P$. falciparum malaria can cause death within hours of infection [25]. Hemolytic anemia, a condition in which the bone marrow is unable to keep up with the pace of red blood cell destruction caused by the infection, may lead to fatigue, weakness, pale skin, rapid heart rate, enlargement of the spleen and shortness of breath, according to the National Institutes of Health (NIH). Cerebral malaria may also occur if infected blood cells block the blood vessels to the brain. Cerebral malaria may lead to swelling of the brain and brain damage [21]. Other serious side effects of malaria include dehydration, liver or kidney failure and breathing problems caused by fluid in the lungs (pulmonary edema). The NIH notes that rupture of the spleen may lead to internal hemorrhage or bleeding, and spreading infection may also lead to meningitis, an inflammation of the meninges, or membranes, that surround the brain and spinal cord.

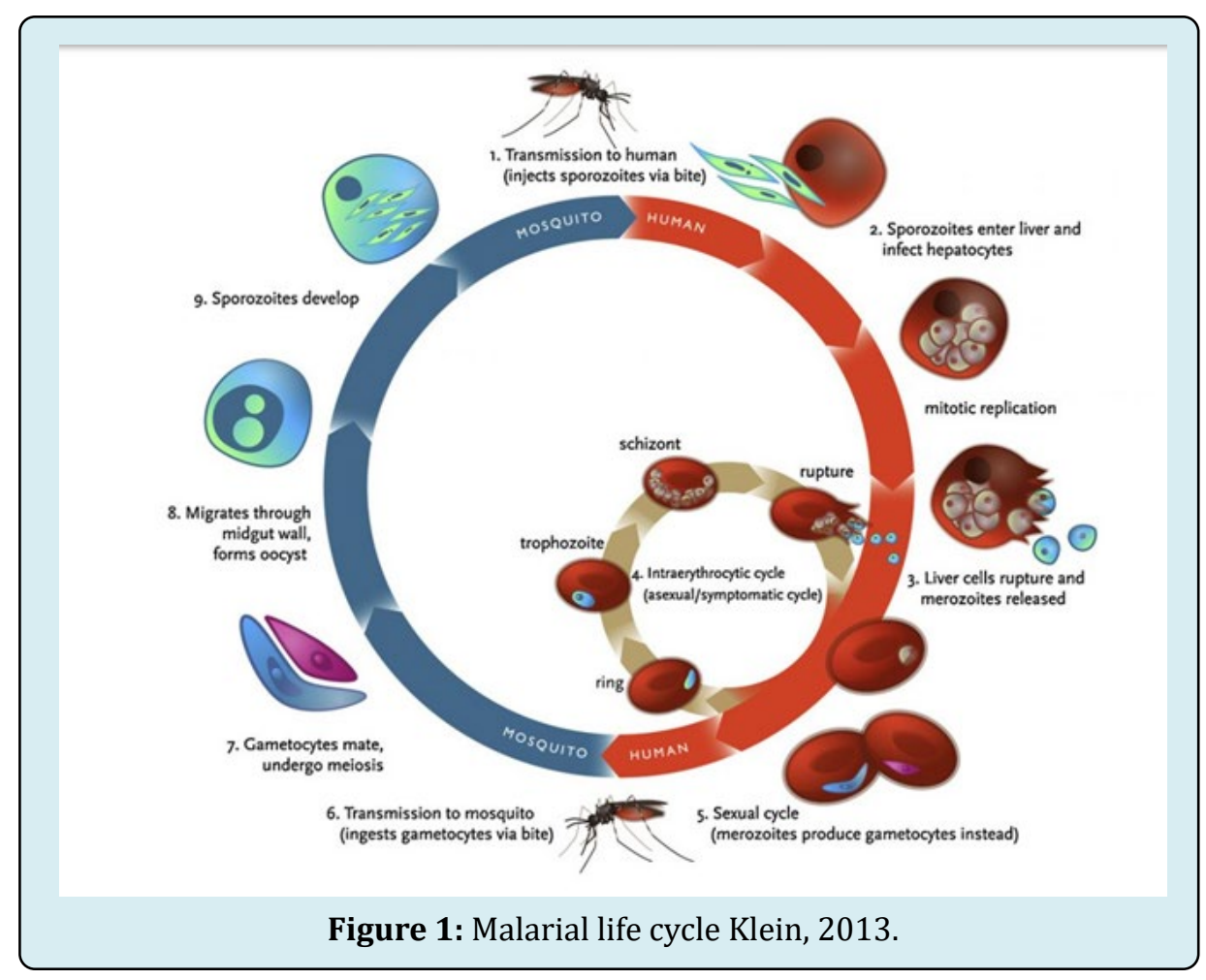

\section{Anti-Malarial Drugs}

Anti-malarial drugs treat or prevent malaria, a disease that occurs in tropical, subtropical, and some temperate regions of the world. Anti-malarial medications, also known as anti-malarial, are designed to prevent or cure malaria. Such drugs may be used for treatment of malaria in individuals with suspected or confirmed infection and for prevention of infection in individuals visiting a malaria-endemic region who have no immunity (malaria prophylaxis). Routine intermittent treatment of certain groups in endemic regions (intermittent preventive therapy).

The effectiveness of early diagnosis and prompt treatment as the principal technical components of the global strategy to control malaria is highly dependent on the 
efficacy, safety, availability, affordability and acceptability of anti-malarial drugs. The effective anti-malarial therapy not only reduces the mortality and morbidity of malaria, but also reduces the risk of resistance to anti-malarial drugs. Therefore, anti-malaria chemotherapy is the keystone of malaria control efforts. Hence the need for a rational antimalaria treatment policy.

\section{Materials and Methods}

The study was a Cross Sectional Descriptive study carried out in Calabar Municipality, Cross River State.

Data were obtained through the use of questionnaires and analyzed Informed consent of respondents were sought

Sampling Size: Three hundred and fifty-five structured questionnaires were administered to both male and female adults including teenagers.

Sampling Techniques: The questionnaires which served as information tools were distributed randomly to cover the major areas in Calabar Municipality especially the metropolis. Some of the places in which the questionnaires were issued include Queen of Angels and Holy Family Catholic church, Akim Market, University of Calabar and Lime Light secondary schools (SSS 3) (Figure 2).

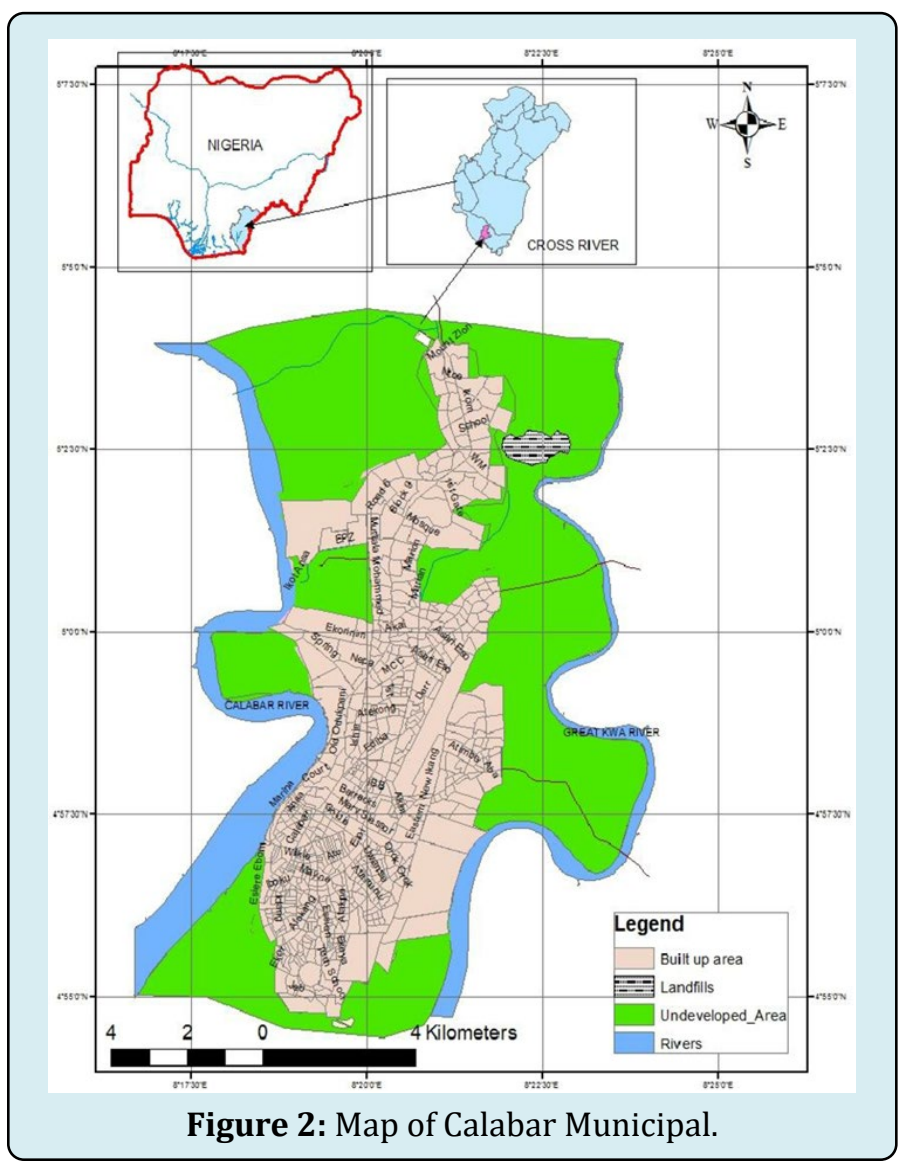

\section{Results}

Three hundred and fifty five questionnaires were administered during a cross sectional descriptive study to access the common anti-malarial drugs used in Calabar metropolis and the following results were obtained.

Table 1 shows the anti-malarial drugs sold based on location. Lonart $15(14 \%)$ was the highest drug sold followed by Amatem 10(9\%) while Maloxine (0\%) was not sold at all in the pharmacies. In the chemist or drug stores, Lonart and Coartem were the most sold drugs while Halfan $(0 \%)$ and Clomaxine (0\%) were not sold at all.

\begin{tabular}{|c|c|c|c|}
\hline Antimalarial & $\begin{array}{c}\text { Chemist store } \\
\text { (\%) }\end{array}$ & $\begin{array}{c}\text { Pharmacy } \\
\text { (\%) }\end{array}$ & Total \\
\hline Lonart & $12(13)$ & $15(14)$ & 27 \\
\hline Waipa & $4(4)$ & $5(5)$ & 9 \\
\hline Amatem & $5(5)$ & $10(9)$ & 15 \\
\hline P-Alaxin & $7(7)$ & $6(6)$ & 13 \\
\hline Lumatem & $4(4)$ & $5(5)$ & 9 \\
\hline Artesunate & $3(3)$ & $8(7)$ & 11 \\
\hline Quinine & $1(1)$ & $2(2)$ & 3 \\
\hline Clatem & $4(4)$ & $4(4)$ & 8 \\
\hline Winithrop & $4(4)$ & $4(4)$ & 8 \\
\hline Komal & $5(5)$ & $4(4)$ & 9 \\
\hline Amalar & $3(3)$ & $2(2)$ & 5 \\
\hline Maldox & $3(3)$ & $2(2)$ & 5 \\
\hline Fansidar & $1(1)$ & $2(2)$ & 3 \\
\hline Malariech & $3(3)$ & $1(1)$ & 4 \\
\hline Laridox & $5(5)$ & $5(5)$ & 10 \\
\hline Artemether & $5(5)$ & $6(6)$ & 11 \\
\hline Fasitab & $1(1)$ & $2(2)$ & 3 \\
\hline Atequine & $0(0)$ & $1(1)$ & 1 \\
\hline Coartem & $9(9)$ & $8(7)$ & 17 \\
\hline Clomaxine & $0(0)$ & $1(1)$ & 1 \\
\hline Maloxine & $2(2)$ & $0(0)$ & 2 \\
\hline Chloroquine & $1(1)$ & $2(2)$ & 3 \\
\hline Halfan & $0(0)$ & $1(1)$ & 1 \\
\hline Combiant & $3(3)$ & $2(2)$ & 5 \\
\hline Comoquine & $0(0)$ & $3(3)$ & 3 \\
\hline Combusunate & $6(6)$ & $5(5)$ & 11 \\
\hline Camosunate & $4(4)$ & $2(2)$ & 6 \\
\hline Total & 95 & 108 & 203 \\
\hline
\end{tabular}

Table 1: Antimalarial drugs sold based on drug stores. 
Table 2 shows the Antimalarial drugs bought based on recommendation. Lumartem was the most sold drugs base on doctors' recommendation 38 (14\%), followed by P-Alaxin $33(12 \%)$ and the least drugs recommended by doctors were Winithrop, fasitab, Komal, Combiant and Comoquine. Nurses recommended Maloxine 21 (35\%) followed by Amatem. while the least recommended drugs were Quinine, Clatem, Maldox, Fansidar, Combusunates. Pharmacists recommended mostly Lumartem 46 (18\%) followed by Coartem 30 (12\%),
Amatem 27 (11\%) and P-Alaxin 22 (9\%) and the least drugs recommended by pharmacists were Maloxine, Comoquine, Combiant, Winithrop while Fasitab, Atequine and Halfan were not recommended at all.

In the self-medication prescription Lumartem 12 (15\%) was the highest bought drugs followed by Coartem 9 (12\%) and Amatem 9 (12\%) while the least was Fansider, Maloxine, Combiant, Comoquine, Laridox and Combusunate.

\begin{tabular}{|c|c|c|c|c|c|c|}
\hline Anti-malarial & Doctor (\%) & Nurse (\%) & Pharmacist (\%) & Self $(\%)$ & Others (\%) & Total \\
\hline Lonart & $28(10)$ & $3(5)$ & $25(10)$ & $7(9)$ & $2(14)$ & 65 \\
\hline Waipa & $3(1)$ & $0(0)$ & $6(2)$ & $2(3)$ & $0(0)$ & 11 \\
\hline Amatem & $25(9)$ & $4(7)$ & 27 (11) & $9(12)$ & $3(21)$ & 68 \\
\hline P-Alaxin & $33(12)$ & $3(5)$ & $22(9)$ & $7(9)$ & $2(14)$ & 67 \\
\hline Lumatem & $38(14)$ & $3(5)$ & $46(18)$ & $12(15)$ & $3(21)$ & 102 \\
\hline Artesunate & $22(8)$ & $3(5)$ & $14(5)$ & $5(6)$ & $1(7)$ & 45 \\
\hline Quinine & $15(5)$ & $1(2)$ & $4(2)$ & $3(4)$ & $1(7)$ & 24 \\
\hline Clatem & $6(2)$ & $1(2)$ & $7(3)$ & $2(3)$ & $1(7)$ & 17 \\
\hline Winithrop & $0(0)$ & $1(2)$ & $1(0.4)$ & $0(0)$ & $0(0)$ & 2 \\
\hline Komal & $1(0.4)$ & $1(2)$ & $0(0)$ & $0(0)$ & $0(0)$ & 2 \\
\hline Amalar & $8(3)$ & $4(7)$ & $5(2)$ & $4(5)$ & $0(0)$ & 21 \\
\hline Maldox & $3(1)$ & $1(2)$ & $4(2)$ & $0(0)$ & $0(0)$ & 8 \\
\hline Fansidar & $5(2)$ & $1(2)$ & $3(1)$ & $1(1)$ & $0(0)$ & 10 \\
\hline Malariech & $2(1)$ & $2(3)$ & $6(2)$ & $1(1)$ & $0(0)$ & 11 \\
\hline Laridox & $8(3)$ & $2(3)$ & $13(5)$ & $3(4)$ & $0(0)$ & 26 \\
\hline Artemether & $11(4)$ & $3(5)$ & $17(7)$ & $5(6)$ & $0(0)$ & 36 \\
\hline Fasitab & $1(0.4)$ & $0(0)$ & $0(0)$ & $0(0)$ & $0(0)$ & 1 \\
\hline Atequine & $3(1)$ & $0(0)$ & $0(0)$ & $1(1)$ & $0(0)$ & 4 \\
\hline Coartem & $29(11)$ & $3(5)$ & $30(12)$ & $9(12)$ & $1(7)$ & 72 \\
\hline Clomaxine & $3(1)$ & $0(0)$ & $1(0.4)$ & $0(0)$ & $0(0)$ & 4 \\
\hline Maloxine & $6(2)$ & $21(35)$ & $1(0.4)$ & $1(1)$ & $0(0)$ & 29 \\
\hline Chloroquine & $6(2)$ & $2(3)$ & $15(6)$ & $3(4)$ & $0(0)$ & 26 \\
\hline Halfan & $3(1)$ & $0(0)$ & $0(0)$ & $0(0)$ & $0(0)$ & 3 \\
\hline Combiant & $1(0.4)$ & $0(0)$ & $4(2)$ & $1(1)$ & $0(0)$ & 6 \\
\hline Comoquine & $1(0.4)$ & $0(0)$ & $1(0.4)$ & $1(1)$ & $0(0)$ & 3 \\
\hline Combusunate & $6(2)$ & $1(2)$ & $1(0.4)$ & $1(1)$ & $0(0)$ & 9 \\
\hline Camosunate & $7(3)$ & $0(0)$ & $2(1)$ & $0(0)$ & 0 & 9 \\
\hline Total & 274 & 60 & 255 & 78 & 14 & 681 \\
\hline
\end{tabular}

Table 2: Antimalarial drugs bought based on recommendation.

Table 3 shows Antimalarial prescription by drug vendors. Lonart was prescribed in a day with 31 (12\%) prescription followed by Coartem 22 (9\%) and Amatem 21 (8\%). The least prescription made in a day were Artemether, Atequine, 
Clomaxine, Maloxine and Halfan. Weekly prescription shows that Lonart was prescribed most with 219 (12\%) followed by Coartem 157 (9\%) and Amatem 150 (8\%) while the least prescriptions were Artemether, Clomaxine, Malariech,
Halfan and Atequine. In a month, the prescription made most were Lonart 876 (12\%), Coartem 628 (9\%) and Amatem $600(8 \%)$. The least prescribed antimalarials still remain Artemether, Clomaxine, Halfan and Atequine.

\begin{tabular}{|c|c|c|c|c|}
\hline Anti-malarial & Day (\%) & Week (\%) & Month (\%) & Total \\
\hline Lonart & $31(12)$ & $219(12)$ & $876(12)$ & 1126 \\
\hline Waipa & $14(5)$ & $103(6)$ & $412(6)$ & 529 \\
\hline Amatem & $21(8)$ & $150(8)$ & $600(8)$ & 771 \\
\hline P-Alaxin & $16(6)$ & $113(6)$ & $452(6)$ & 581 \\
\hline Lumatem & $15(6)$ & $112(6)$ & $448(6)$ & 565 \\
\hline Artesunate & $15(6)$ & $106(6)$ & $424(6)$ & 545 \\
\hline Quinine & $4(2)$ & $25(1)$ & $96(1)$ & 125 \\
\hline Clatem & $13(5)$ & $89(5)$ & $356(5)$ & 458 \\
\hline Winithrop & $11(4)$ & $78(4)$ & $312(4)$ & 401 \\
\hline Komal & $10(4)$ & $68(4)$ & $272(4)$ & 350 \\
\hline Amalar & $6(2)$ & $45(2)$ & $180(2)$ & 231 \\
\hline Maldox & $7(3)$ & $47(3)$ & $188(3)$ & 242 \\
\hline Fansidar & $5(2)$ & $34(2)$ & $136(2)$ & 175 \\
\hline Malariech & $2(1)$ & $13(1)$ & $52(1)$ & 67 \\
\hline Laridox & $9(4)$ & $64(4)$ & $256(4)$ & 329 \\
\hline Artemether & $1(0.4)$ & $10(1)$ & $40(1)$ & 51 \\
\hline Fasitab & $5(2)$ & $32(2)$ & $128(2)$ & 165 \\
\hline Atequine & $2(1)$ & $15(1)$ & $60(1)$ & 77 \\
\hline Coartem & $22(9)$ & $157(9)$ & $628(2)$ & 857 \\
\hline Clomaxine & $2(1)$ & $13(1)$ & $52(1)$ & 67 \\
\hline Maloxine & $2(1)$ & $16(1)$ & $64(1)$ & 82 \\
\hline Chloroquine & $5(2)$ & $32(2)$ & $128(2)$ & 165 \\
\hline Halfan & $2(1)$ & $15(1)$ & $60(2)$ & 77 \\
\hline Combiant & $10(4)$ & $72(4)$ & $288(4)$ & 370 \\
\hline Comoquine & $5(2)$ & $36(2)$ & $144(2)$ & 185 \\
\hline Combusunate & $12(5)$ & $85(5)$ & $340(5)$ & 437 \\
\hline Camosunate & $9(4)$ & $61(3)$ & $244(3)$ & 314 \\
\hline Total & 256 & 1810 & 7236 & 9302 \\
\hline
\end{tabular}

Table 3: Anti-malarial prescription by drug vendors.

The daily prescription made in the chemist stores from table 4 reveals that Lonart 9 (10\%), P-Alaxin 8 (10\%) and Coartem 7 (9\%) were the most prescribed anti-malarial while Chloroquine, Fasitab, Fansidar, Maldox and Quinine were the least prescribed. Atequine, Clomaxine, halfan and Comoquine were not prescribed. In a week, the most prescribed antimalarials were Lonart 62 (11\%), P-Alaxine $55(10 \%)$ and Coartem 54 (10\%) while the least prescribed were Chloroquine, Fasitab, Quinine and Fansider. Halfan, Comoquine and Atequine were not prescribing at all. The most prescribed antimalarials in the month were Lonart 248 (11\%), P-Alaxin 220 (10\%) and Coartem 216 (10\%). Chloroquine, Fasitab and Fansider were the least prescription made while Comoquine, Halfan, Clomaxine and Atequine were still not prescribing at all. 


\begin{tabular}{|c|c|c|c|c|}
\hline Lonart & $9(10)$ & $62(11)$ & $248(11)$ & 319 \\
\hline Waipa & $4(5)$ & $35(6)$ & $140(6)$ & 180 \\
\hline Amatem & $5(6)$ & $32(6)$ & $128(6)$ & 165 \\
\hline P-Alaxin & $8(10)$ & $55(10)$ & $220(10)$ & 283 \\
\hline Lumatem & $6(7)$ & $39(7)$ & $156(7)$ & 201 \\
\hline Artesunate & $4(5)$ & $28(5)$ & $112(5)$ & 144 \\
\hline Quinine & $1(1)$ & $4(1)$ & $12(1)$ & 21 \\
\hline Clatem & $5(6)$ & $32(6)$ & $128(6)$ & 165 \\
\hline Winithrop & $2(2)$ & $20(5)$ & $92(4)$ & 144 \\
\hline Komal & $3(2)$ & $17(3)$ & $68(3)$ & 87 \\
\hline Amalar & $2(2)$ & $15(3)$ & $60(3)$ & 77 \\
\hline Maldox & $1(1)$ & $11(2)$ & $44(2)$ & 56 \\
\hline Fansidar & $1(1)$ & $6(1)$ & $24(1)$ & 31 \\
\hline Malariech & $1(1)$ & $5(1)$ & $20(1)$ & 87 \\
\hline Laridox & $4(5)$ & $21(4)$ & $84(4)$ & 134 \\
\hline Artemether & $1(1)$ & $4(1)$ & $10(0.4)$ & 139 \\
\hline Fasitab & $1(1)$ & $4(1)$ & $16(1)$ & 21 \\
\hline Atequine & $0(0)$ & $0(0)$ & $0(0)$ & 0 \\
\hline Coartem & $7(9)$ & $54(10)$ & $216(10)$ & 278 \\
\hline Clomaxine & $0(0)$ & $0(0)$ & $0(0)$ & 0 \\
\hline Maloxine & $2(2)$ & $16(3)$ & $64(3)$ & 77 \\
\hline Chloroquine & $1(1)$ & $4(1)$ & $16(1)$ & 21 \\
\hline Halfan & $0(0)$ & $0(0)$ & $0(0)$ & 0 \\
\hline Combiant & $5(6)$ & $32(6)$ & $134(6)$ & 165 \\
\hline Comoquine & $0(0)$ & $0(0)$ & $0(0)$ & 0 \\
\hline Combusunate & $6(7)$ & $42(7)$ & $160(7)$ & 216 \\
\hline Camosunate & $4(5)$ & $27(5)$ & $108(5)$ & 139 \\
\hline Total & $\mathbf{8 2}$ & $\mathbf{5 6 6}$ & $\mathbf{2 2 6 0}$ & $\mathbf{2 9 0 8}$ \\
\hline
\end{tabular}

Table 4: Antimalarial drugs prescriptions made in the chemist store.

The total sum of the prescription made in a day, week and month shows that Lonart, P-Alaxin and Coartem were the most prescription made while Chloroquine, Fasitab and Fansider were the least prescribed anti-malarials. Halfan, Clomaxine, Comoquine and Atequine showed no prescription. The results obtained from Table 5 shows that in a day, Lonart 22 (13\%), Amatem 17 (10\%) and Coartem 15 (9\%) were the most prescribed anti-malarial drugs made in the pharmacies while Malariech, Atequine, Halfan and Quinine were the least prescribed and Maloxine was not prescribed at all. In a week, Lonart 157 (12\%), Amatem 118 (9\%) and Coartem 103 (8\%) were the most prescribed anti-malarials. Malariech, Clomaxine, Halfan and Atequine showed least prescription while Maloxine was not prescribe. The most prescribed anti- malarial drugs in a month were Lonart 628 (12\%), Amatem 472 (9\%) and Coartem 412 (8\%). The least prescriptions made were Malariech, Atequine and Halfan. Maloxine was not still prescribe.

\begin{tabular}{|c|c|c|c|c|}
\hline Anti-malarial & Day & Week & Month & Total \\
\hline Lonart & $22(13)$ & $157(12)$ & $628(12)$ & 807 \\
\hline Waipa & $10(6)$ & $68(5)$ & $272(5)$ & 350 \\
\hline Amatem & $17(10)$ & $118(9)$ & $472(9)$ & 607 \\
\hline P-Alaxin & $8(5)$ & $58(5)$ & $232(5)$ & 298 \\
\hline Lumatem & $9(5)$ & $73(6)$ & $292(6)$ & 375 \\
\hline Artesunate & $11(6)$ & $78(6)$ & $312(6)$ & 401 \\
\hline Quinine & $3(2)$ & $21(2)$ & $84(2)$ & 108 \\
\hline Clatem & $8(5)$ & $57(5)$ & $228(5)$ & 293 \\
\hline Winithrop & $9(5)$ & $58(5)$ & $240(5)$ & 334 \\
\hline Komal & $7(4)$ & $51(4)$ & $204(4)$ & 262 \\
\hline Amalar & $4(2)$ & $30(2)$ & $120(2)$ & 154 \\
\hline Maldox & $6(3)$ & $36(3)$ & $144(3)$ & 185 \\
\hline Fansidar & $4(2)$ & $28(2)$ & $112(2)$ & 144 \\
\hline Malariech & $1(1)$ & $8(1)$ & $32(1)$ & 41 \\
\hline Laridox & $5(3)$ & $43(3)$ & $272(3)$ & 273 \\
\hline Artemether & $1(1)$ & $5(0.4)$ & $30(1)$ & 386 \\
\hline Fasitab & $4(2)$ & $28(2)$ & $112(2)$ & 144 \\
\hline Atequine & $2(1)$ & $15(1)$ & $60(1)$ & 77 \\
\hline Coartem & $15(9)$ & $103(8)$ & $412(8)$ & 530 \\
\hline Clomaxine & $2(1)$ & $13(1)$ & $52(1)$ & 66 \\
\hline Maloxine & $0(0)$ & $0(0)$ & $0(0)$ & 0 \\
\hline Chloroquine & $4(2)$ & $28(2)$ & $112(2)$ & 144 \\
\hline Halfan & $2(1)$ & $15(1)$ & $60(1)$ & 77 \\
\hline Combiant & $5(3)$ & $40(3)$ & $154(3)$ & 185 \\
\hline Comoquine & $5(3)$ & $36(3)$ & $144(3)$ & 185 \\
\hline Combusunate & $6(3)$ & $43(3)$ & $180(3)$ & 231 \\
\hline Camosunate & $5(3)$ & $34(3)$ & $136(3)$ & 77 \\
\hline Total & $\mathbf{1 7 5}$ & $\mathbf{1 2 4 4}$ & $\mathbf{4 9 9 6}$ & $\mathbf{6 4 1 5}$ \\
\hline
\end{tabular}

Table 5: Anti-malarial prescriptions made in the pharmacies.

The overall sum total of the most prescribed antimalarial were Lonart, Amatem and Coartem, Halfan, Atequine and Malariech were the least prescribed while Maloxine was not prescribe. The administration of questionnaires by gender presented in Figure 3. Of the 355 questionnaires administered.55\% females participated while 45 were males. The anti-malarial drugs bought based on symptoms shown in Figure 4. High body temperature was the highest symptom 
for the purchase of anti-malarial drugs (35.5\%) followed by those who had headache(25\%), body pains (20\%), loss of appetite $(14 \%)$ and the least symptoms that prompted respondents to buy anti-malarial drugs was vomiting (6\%). Figure 5 shows the places where Anti-malarial drugs are bought. Peoples mostly bought anti-malarial drugs in the pharmacy $(53 \%)$ followed by chemist store $(25 \%)$, hospital pharmacy $(15 \%)$ and lastly in health centre $(8 \%)$.

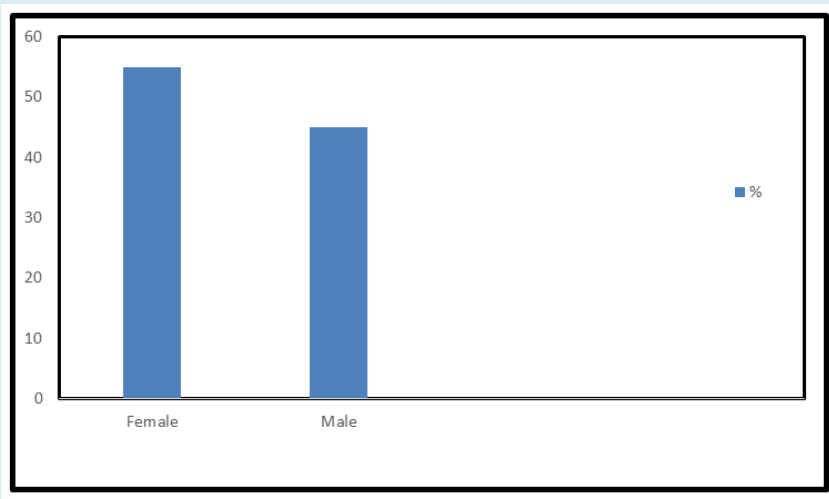

Figure 3: Administration of questionnaires by gender.

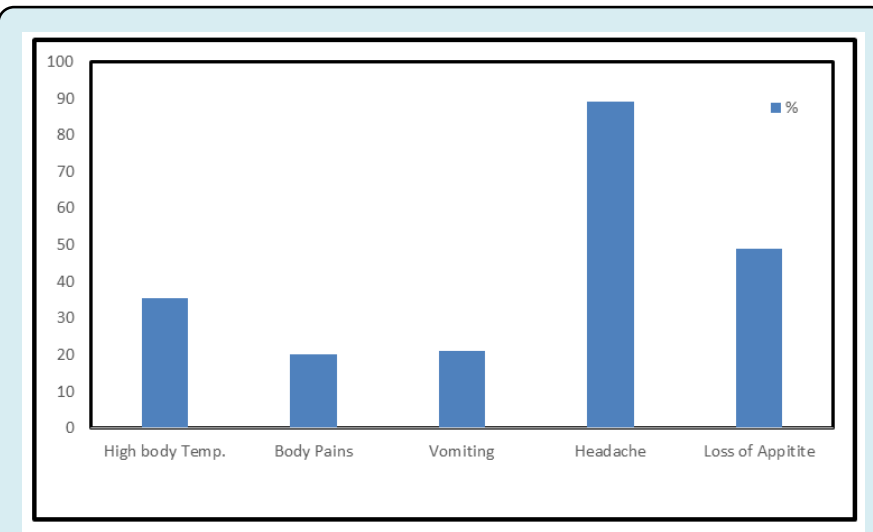

Figure 4: Anti-Malarial drugs Bought based on symptoms.

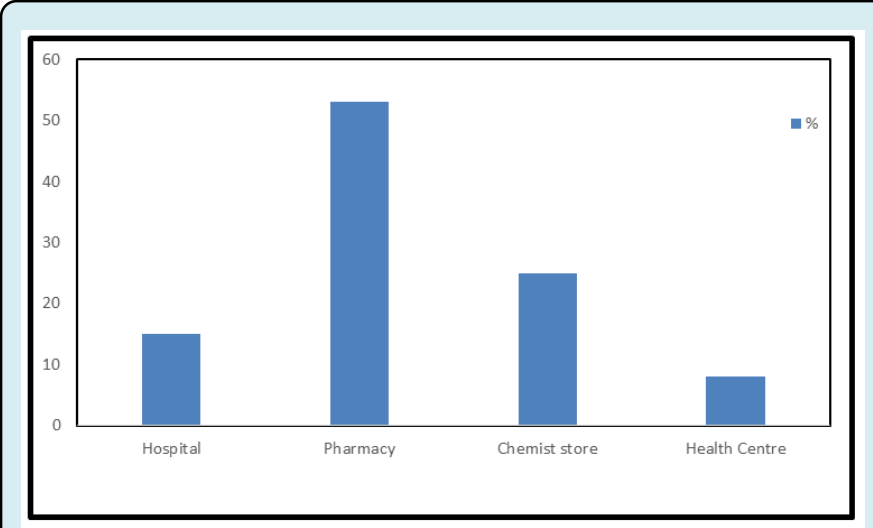

Figure 5: Places where anti-malarial drugs were bought.
The assessment of participants according to antimalarial drugs consumption is presented in Figure 6. The respondents who feel perfectly alright were $60 \%$, while those who feel fairly okay after antimalarial consumption were $28 \%$ and those who could not feel quite alright after anti-malarial consumption were $12 \%$ and none of the respondents show no cure.

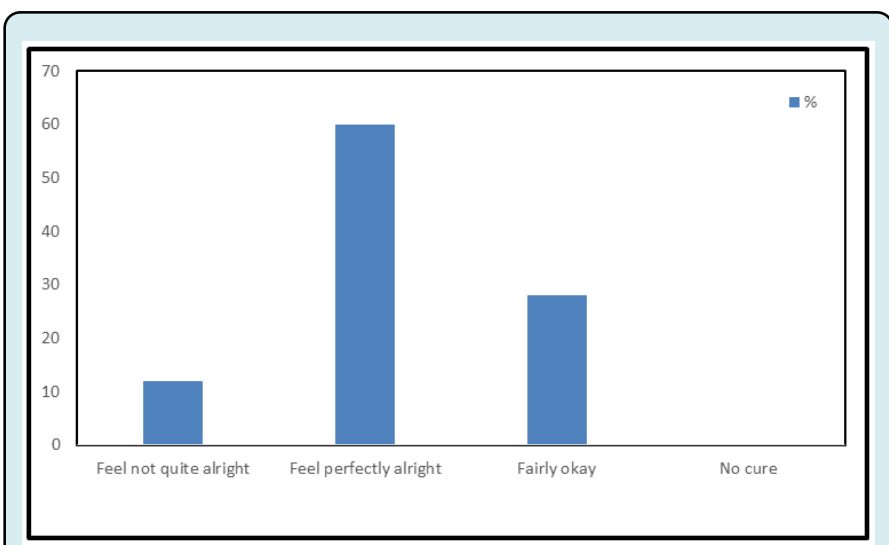

Figure 6: Assessment of participant according to antimalarial drugs consumption.

\section{Discussion}

The descriptive cross-sectional studies to assess the commonly used anti-malarials among urban dwellers in Calabar metropolis revealed that the most sold antimalarial drugs based on location were the ACTs (Artemisinin Combination Therapies) which is made up of Artemether and Lumefantrine $(\mathrm{A}+\mathrm{L})$. This is similar to the work done by Modupe IB, et al [28] which showed $58.1 \%$ of $\mathrm{A}+\mathrm{L}$ compare to all other available anti-malarials sold both in the chemist stores and pharmacies. Also, the most common anti-malarials that were bought based on recommendation by health practioners were Lumatem, Coartem, Lonart and Amatem which are all ACTs and in line with the WHO and Federal Ministry of Health recommended anti-malarials for first line treatment of uncomplicated malarial [29]. This indicates that perhaps all the health practitioners and even individuals are fully aware of this treatment guideline which has in turn made the recommendation of these anti-malarials significant.

Prescriptions made in the pharmacies and chemist stores showed that Lonart, Amatem and Coartem were highly prescribed in the pharmacies. This is because these anti-malarials apart from being ACTs were highly available [30]. It is also observed that these anti-malarials were purchased more in the pharmacies than the chemist stores and this is due to the fact that pharmacies are common in the urban centres. Figure 4 indicated that the most common 
and highest symptoms of malaria were headache and loss of appetite. These are parts of the first symptoms of malaria. These symptoms showed that the prescription made by drugs vendors were based on clinical signs and symptoms of the disease and this is perhaps the reason for high patronage of ACTs.

The results obtained show that the pattern of antimalarial prescriptions were dominated by ACTs as seen in Tables 3-5 and this corresponds with the work done by Modupe IB, et al. [28]. Prescribers tend to adhere more to national treatment guideline [31] because of drug resistance which is a major challenge in the fight against malaria. Prescriptions by various health practitioners revealed that Lonart, Lumatem and Coartem (ACTs) were prescribed more by doctors and pharmacists. This shows that they follow the current WHO guidelines for malaria treatment which is consistent as observed in previous reports that prescribers in hospitals tend to adhere more to national treatment guideline [31]. It is also obtained from table 2 that doctors made the highest prescriptions of ACTs which is also due to the strict adherence to the national treatment guidelines. It is also seen from previous reports that $55 \%$ of doctors stated that they utilized the current National anti-malarial guideline as the first line treatment of uncomplicated malaria [32].

Observation from Figure 4 shows that there was high level of presumptive diagnoses and treatment of malaria as anti-malarials were purchased based on clinical symptoms observed and this is one of the reasons why ACTs were highly utilized compared to others [33]. Self -prescription of ACTs as observed from table 2 contributed over $39 \%$ of the total ACTs prescribed and bought in the urban centres. Jombo GTA, et al. [34] recorded 34\% of self-prescription medication and this was found to be significant.

The survey showed that despite changes in the national guidelines for treatment of malaria in Nigeria, over 26\% of monotherapy anti-malarials were recommended in the urban centre. This could be due to the high cost of ACTs [15]. Monotherapy is no longer recommended in the treatment of malaria in Nigeria due to the development of resistant strain by the parasite [35]. Artemisinin derivatives used as monotherapy is no longer encouraged as WHO in order to preserve the efficacy of artemisinins as an essential component of life-saving ACTs, has called for a ban on the use of oral administration of monotherapies at various levels including manufacturers, international drugs suppliers, national health authorities and funding agencies involving in supporting essential anti-malarial medicine [36,37].

It is observed that enough information on the use of ACTs have been made and is still ongoing despite the cost implications of most ACTs and efficacies. Efficacies are one of the reasons why they tend to be a high purchase of ACTs in Calabar metropolis [38-41]. ACTs have been established to improve the management of malaria over all other antimalarial in recent time and efforts are been made by health workers to prescribed these anti-malarials always [15].

\section{Conclusion}

The results of the survey on commonly used antimalarial drugs in Calabar metropolis have shown that Lonart, Coartem, Lumarterm, Amatem and P-Alaxin are the most commonly used anti-malarials prescribed by health practitioners and bought by the respondents.

\section{References}

1. Henry GM, Dawit GA, Temesgen TZ (2012) Prevalence and risk factors of malaria in Ethiopia. Malaria Journal 11: 195.

2. Abaaku BK, Koram KA, Binta FN (2004) Antimalarial drug use among care givers in Ghana. African Health Sciences 4(3): 171-177.

3. Sudhanshu S, Neerja P, Jain DC, Bhakuni RS (2003) Antimalarial agents from plant source. Current Science Association 85(9): 1314-1329.

4. Parija SC, Praharaj I (2008) Drug resistance in malaria. Indian J Medical Microbiology 29(3): 243-248.

5. WHO (2013) Universal Access to Malaria Diagnostic Testing-an operational manual. World Health Organisation pp: 160 .

6. Hemingway J, Bates I (2003) Malaria: past problems and future prospects. After more than a decade of neglect, malaria is finally black on the agenda for both biomedical research and public health politics. EMBO Rep 4: 29-31.

7. Ukpai OM, Ajoku EI (2001) The Prevalence of Malaria in Okigwe and Owerri Areas of Imo State. The Nigeria Journal of Parasitology 22(192): 43-48.

8. Archibong OD, Ibor UA, Oyama IO, Duke EE, Efeffiom EE, et al. (2016) Prevalence of Malaria and Typhoid Fever Co-infection among Febrile Patients Attending College of Health Technology Medical Centre in Calabar, Cross River State, Nigeria. Int J Curr Microbiol App Sci 5(4): 825-835.

9. Oshikoya KA (2007) Antimalarial prescriptions for children presenting with uncomplicated malaria to a teaching hospital in Nigeria after the change of National Guidelines for malaria treatment. World Journal of medical sciences 2(1): 49-53. 
10. Pasvol G (2005) Infectious Disease Clinical 19: 211-240.

11. Herchline TE, Bronze MS, Simon RQ (2019) Malaria Medication. Medscape.

12. Warhurst DC (1987) Antimalarial Drugs. Drugs 33(1): 50-65.

13. Anthony KM, Sham L, Bonnie C, Kristian SH, Siân C, et al. (2013) Treatment of fevers prior to introducing rapid diagnostic tests for malaria in registered drug shops in Uganda. Malaria Journal 12: 131.

14. Martin RE, Ginsburg H, Kirk K (2008) Membrane transport protein of the malaria parasite. Molecular Microbiology 74(3): 519-528.

15. Omole MK, Onademuren OT (2010) A survey of Antimalarial Drug use practices among urban Dwellers in Abeokuta, Nigeria. Afr J Biomed Res 13: 1-7.

16. Pharmanews (2007) Nigeria's Health Journal January 29(2): 14-15.

17. Rathod PK, McErlean T, Lee PC (1997) Variations in frequencies of drugs resistance in Plasmodium falciparum. Proc Natl Acad Sci 94(17): 9389-9393.

18. Ananya M (2017) Malaria Epidemiology: Medical life science multidrug-resistant falciparum malaria in Thailand. Tropical Medicine for International Health 11: 1653-1660.

19. Cox FEG (2010) History of the discovery of the malaria parasites and their vectors. Parasites \& vectors 3(1): 5 .

20. Lambert PH (2003) Malaria: Past and Present.

21. Arora DR, Arora B (2007) Medical parasitology. $2^{\text {nd }}$ (Edn.), CBS Publishers, New Delhi, pp: 74-75.

22. Granberg AL (2014) The Life Cycle of malaria.

23. Cox-Singh J, Davis TME, Lee-Kim S, Shamsui SS, Matusop A, et al. (2008) Plasmodium knowlesi malaria in humans is widely distributed and potentially life threatening. Clin Infect Dis 46(2): 165-171.

24. Tricia M (2017) Symptom and effects of malaria.

25. Kihara M, Carter JA, Newton CR (2006) The effects of Plasmodium falciparum on cognition: a systematic review. Trop Med Int Health 11(4): 386-397.

26. White NJ (2011) Determinants of relapse periodicity in Plasmodium vivax malaria. Malaria Journal 10: 297.

27. Gonzalezet R, Esperanca S, Clara M (2018) Current knowledge and challenges of antimalarial drugs for treatment and prevention in pregnancy. Expert Opin pharmacother 11(8): 1277-1293.

28. Modupe IB, Hannah D, Jonah YP, Emmanuel O (2014) Prescription patterns of Antimalaria drugs in a Teaching Hospital in Nigeria. British Biomedical Bulletin 2(1): 267-276.

29. Pongtavornpinyo W, Hastings IM, Dondorp A, White LJ, Maude RJ, et al. (2009) Probability of emergence of antimalarial resistance in different stages of the parasite life cycle. Evol Appl 2(1): 52-61.

30. Ezenduka CC, Ogbonna BO, Ekwunife OI, Okonta MJ, Esimone CO (2014) Drugs use pattern for uncomplicated malaria in medicine retail outlets in Enugu urban, SouthEast Nigeria: implication of malaria Treatment Policy. Malar J 13: 243.

31. Gbotosho GO, Happil CT, Ganiyu A, Ogundahunsi OA, Sowunmi A, et al. (2009) Potential Contribution of prescription practices to the emergence and spread of Chloroquine resisitance in South-West Nigeria: Caution in the use of Artemisinin Combination Therapy. Malaria J 8: 313.

32. Nkechinyere EH, Tolulope FO, Chimere OA (2012) Utilization of the current national antimalarial treatment guidelines among doctors in army hospitals in Lagos, Nigeria. Open Journal of Preventive Medicine 2(3): 390393.

33. WHO (2015) WHO Model List of Essential Medicines. World Health Organization.

34. Jombo GTA, Mbaawuaga EM, Denen AP, Alao 00, Peters EJ, et al. (2010) Choices of drugs for Self-treatment of malaria among adult women in a Nigerian city: Implications for the success of the ongoing 'roll back' malaria programme.

35. WHO (2010) World Malaria report 2010. World Health Organization, Geneva.

36. WHO (2017) Withdrawal of oral artemisinin-based monotherapies. World Health Organization, Geneva.

37. Godwin AC (2017) FG ban Chloroquine, artemisinin monotherapies. Daily Post.

38. González R, Hellgren U, Greenwood B, Menéndez C (2014) Mefloquine safety and tolerability in pregnancy: a systematic literature review. Malaria J 13: 75.

39. Seifert K, Simon LC (2010) Antiprotozoal Agents: Antibiotic and chemotherapy. 
40. WHO (2011) World malaria report. World Health Organization.
41. WHO (2015) Guidelines for the treatment of malaria. $3^{\text {rd }}$ (Edn.), World Health Ortganization. 